\title{
Application of Design Thinking for Service Innovation: Current Practices, Expectations and Adoption Barriers
}

\author{
Frederike Engberts \\ University of Amsterdam Business School/ KPMG \\ fred.engberts@gmail.com
}

\author{
Hans P. Borgman \\ University of Amsterdam Business School \\ h.p.borgman@uva.nl
}

\begin{abstract}
There is an increasing interest from both academics and practitioners on the application of Design Thinking (DT) for innovation efforts. This study explores the current real-life application of DT within five large Dutch multinationals for service innovation projects. It aims to develop an understanding of how and why DT is applied, and what the benefits and challenges are of the adoption. Based on existing literature, five propositions are developed that guide the data collection and analysis for eight case studies on service innovation projects where DT was applied. The results show that DT is applied as a mindset or 'way-of-thinking', supported by methods, processes and tools. Expected benefits that drive its application are increased customer value delivered by service innovations, as well as an improved ability to deal with complexity. Adoption of DT is hampered by the individual's understanding of DT as well as uncertainty avoidance. Based on the discussion of these findings within the extant literature, we propose a model comprising four interconnected factors driving DT adoption.
\end{abstract}

\section{Introduction}

Design Thinking (DT), as an approach to innovation and business challenges, is currently attracting a large (and increasing) amount of interest in both management practice as well as academic literature [1]. In the past five years, DT has featured prominently in publications such as The Economist, Harvard Business Review, Business Week, The Wall Street Journal, and The New York Times [2], as well as in academic journals like Academy of Management Journal, Organization Studies and Research Policy. However, DT is not a new approach, as the first publication on DT dates back to 1987 by Rowe [3, 4]. The slow (initial) adoption does explain why, to date, very little research has been conducted on the organizational application of the approach beyond more anecdotal examples in the aforementioned publications [2]. Some empirical studies do exist, typically in a controlled environment with a student sample [1], and some conceptual studies do theorize about its possible effectiveness [2, 5]. We were, however, unable to locate studies that methodically study real-life DT experiences and that offer insights that help guide companies utilizing DT.

Given the origins of the DT approach in the architecture and product design practices, it is not surprising that almost all of the aforementioned anecdotal evidence comes from companies designing, producing and selling physical products. In those environments, the evidence suggests that DT can be of great help for business and innovation challenges [1, 6] and helps to significantly improve customer experiences $[5,7]$. As such it has the potential of uncovering new ways of value creation, something that is also at the heart of many service innovation projects [8]. With services making up more than $70 \%$ of GDP in advanced economies [9], and a tremendous need for service innovation in an effort to fuel economic growth [10], this potential is of considerable interest. Therefore, this study will focus on exploring the real-life experiences in applying DT for value creation in service innovation projects. By doing so, this study answers the call for a greater understanding of the DT practice $[1,2,5]$ and enhances our understanding of the ability to design and innovate service systems by using a DT approach [9, 11, 12]. As a result, the focus of this study lies within the question: "Why and how is design thinking applied for service innovation projects, and what are the benefits of, and challenges to adoption of design thinking?'.

In an effort to answer this question, the study will stay close to the heart of DT: "conducting research to inspire better hypotheses, rather than to merely test them; resulting in improved outcomes." [2]. As such, exploratory research is conducted which will be presented in five sections. The next section 'theoretical background' will focus on proposition 
development based on theories of design and organization studies as well as psychology, service and innovation science. This is followed by a more detailed description of the case study design, after which results of the data analysis will be presented in 'findings'. In 'discussion and future research' we reflect on the insights gained for the academic debate as well as to inform practitioners, including a brief discussion of limitations and future research.

\section{Theoretical Background}

In order to be able to study the developed research question, first an understanding of DT needs to be established. This is specifically important in the case of DT as despite the encouragement of application by both academics and practitioners, the belief on what form it should take differs between and amongst them. Within the academic literature some argue for DT as being a form of reasoning [4] while others describe it being a specific process [3, 13]. A similar divergence exists amongst practitioners, as the terms 'process' and 'way-of-thinking' are used intertwiningly across and within literature [13]. This difference in beliefs is also indicated by the number of different processes suggested by practitioners, as can be seen in the research of Liedtka [2]. As a result of these divergent opinions, a generally accepted theory and definition of DT has yet to emerge [2, 4]. Nonetheless, we observe a shared understanding of DT as an 'approach' $[1,2,5,7,14,15]$, with more empirical studies typically observing or proposing stages or formal methods $[1,2,5]$. As a result, the first and elemental proposition describes the 'application form' of DT as PO - Design Thinking applied in practice is done by following stages or formal methods.

\subsection{Complexity}

In answering why DT is being used, literature argues that it is helpful for a range of business challenges [1], particularly those involving high complexity [7] such as so-called 'wicked problems'. Wicked problems lack both definite formulations and solutions, and face high levels of uncertainty [16, 17]. Designers often have to deal with these wicked problems that do not lend themselves to analytical, linear problem solving. As a result, DT uses a more synthetic approach to problem solving and has developed specific, professional practices to deal with open and complex systems [4]. This approach reflects the holistic and contextual consideration DT often takes; not only focusing on the specific issue at hand but also the system in which it exists [3]. More particularly, services are part of systems that are characterized as highly complex, typically involving many people, a range of technologies and multiple organizations that are linked to create value $[8,18]$. Therefore, innovation efforts that involve services should be a particularly good fit with DT, leading to P1 - Application of Design Thinking improves the ability to solve complex service innovation problems.

\subsection{Customer Value}

Rapid technological developments, as well as a more interconnected business landscape cause organizations to face 'wicked' problems more and more. As a result, the need for strategies and tools that help solving them increases as well $[4,7]$. To sustain a competitive advantage in this complex environment, businesses are increasingly focusing on how they can deliver superior customer value [19]. Crucial to reach 'superiority' in customer value creation and delivery, is that it connects with actual customer needs [5, 20] as value is ultimately determined by the beneficiary $[8$, 21]. As such, a deep understanding of customer needs is required [22]. Within the literature on DT, a shared central principle is that of 'human-centricity', ensuring that no matter the size of the project, the customer need is always at the forefront and fulfilled in such a way that it creates value $[2,5,7,13,14,15]$. According to Vargo et al. [8] "value depends on the capabilities a system has to survive and accomplish other goals in its environment". Therefore, it is crucial to ensure that an offering can accomplish such goals, delivering on the intended or expected value. To minimize the risk of mismatch and to test an offering's applicability, experimentation can be used [2], another key principle of DT $[2,3,5,7,13]$. Taken together, this leads to $P 2$ - Application of design thinking improves the ability to create solutions that deliver customer value.

\subsection{Understanding Design Thinking}

In order for the aforementioned expected influences to be realized, a prerequisite is that DT is adopted by employees and subsequently applied during projects. However, seen by the slow uptake of DT in practice $[2,5]$, there is reason to believe adoption barriers exist. A first barrier can be found within the underdevelopment of the topic. Individuals might not be aware of what the approach involves or potentially refer to different frameworks due to the degree of information ambiguity, known to be avoided by individuals [23, 24]. This ambiguity originates from the diversity of beliefs and opinions amongst 


\begin{tabular}{|l|l|l|}
\hline Industry & Innovation Projects (case number) & Interviewees (interviewee reference) \\
\hline \multirow{2}{*}{ Telecom } & Customer Journey Innovation (1) & $\begin{array}{l}\text { - Customer Experience Manager (A) } \\
\text { - Service Designer - (B) }\end{array}$ \\
\cline { 2 - 3 } & Service Innovation (2) & - Service Designer - (B) \\
\hline \multirow{2}{*}{ Telecom } & Proposition Development (3) & $\begin{array}{l}\text { - Segment Marketer - (C) } \\
\text { - Business Analyst - (D) }\end{array}$ \\
\cline { 2 - 3 } & Product \& Service Innovation (4) & - Innovation Manager - (E) \\
\hline \multirow{2}{*}{ Banking } & Digital Tool (5) & $\begin{array}{l}\text { - Service Designer - (F) } \\
\text { - Business Manager Digital Client Strategy - (G) }\end{array}$ \\
\cline { 2 - 3 } & Digital Platform (6) & - Business Manager Digital Client Strategy - (G) \\
\hline Banking & Digital Service Innovation (7) & - Customer Journey Expert - (H) \\
\hline Advisory & Digital Tool (8) & - Business Analyst - (I) \\
\hline
\end{tabular}

Table 1. Overview of cases and interviews

practitioners about what DT is. Companies such as IDEO, Stanford Design School and Darden Business School all refer to different processes and definitions, as can be seen in the comparison made by Liedtka [2]. A lack of a generally accepted theory could be a contributing factor. Next to that, the logic of DT is highly synthetic, focusing on real world experiences [15]. This is contrasting to the rational-analytical logic, home to management, engineering and marketing $[1,25,26]$. This difference in so called 'thought-worlds'- a shared set of understandings by a community of persons - could form a potential barrier as individuals may find ideas meaningless or reject them when not aligned with their own thought-world $[25,27]$. This leads to $P 3$ - The adoption of design thinking is limited by an individual's understanding of the approach.

\subsection{Avoiding Uncertainty}

Whether or not low adoption can be linked to the academic underdevelopment of the approach is an open question we do not address here. Low adoption, in turn, does explain the limited availability of published research looking at the outcomes of projects driven by DT. This issue is also intrinsically difficult, as DT relies on a creative approach and abductive reasoning. This is highly dependent on an individual's interpretation and thus makes it often infeasible to predict the specific outcomes and assess the effectiveness of DT [28].

When faced with uncertainty, there is a natural tendency for people in organizations to disengage from medium to long-term commitments and focus on short-term commitments instead [24]. Also, investing time and money in projects with uncertain outcomes or without a clear prospect for success (and using a DT approach will likely contribute to this) will make employees wary to 'sign up' for such projects [29]. This leads to the final proposition P4 - The adoption of design thinking is limited by an individual's uncertainty avoidance.

\section{Methodology and Cases}

As the research question suggests, the intent of this study is to explore and provide insight into the application, expectations and adoption of DT. To investigate this, real-life cases were studied [30] which were selected based on a combination of convenience and snowball sampling [31] as a result of the limited availability of use cases for which interviewee referral was necessary. However, the cases were required to fit several criteria to ensure they all included the characteristics identified in the research question and propositions [31]. First of all, cases needed to focus on real-life service innovation projects to ensure the approach was made tangible as well as to reduce the 


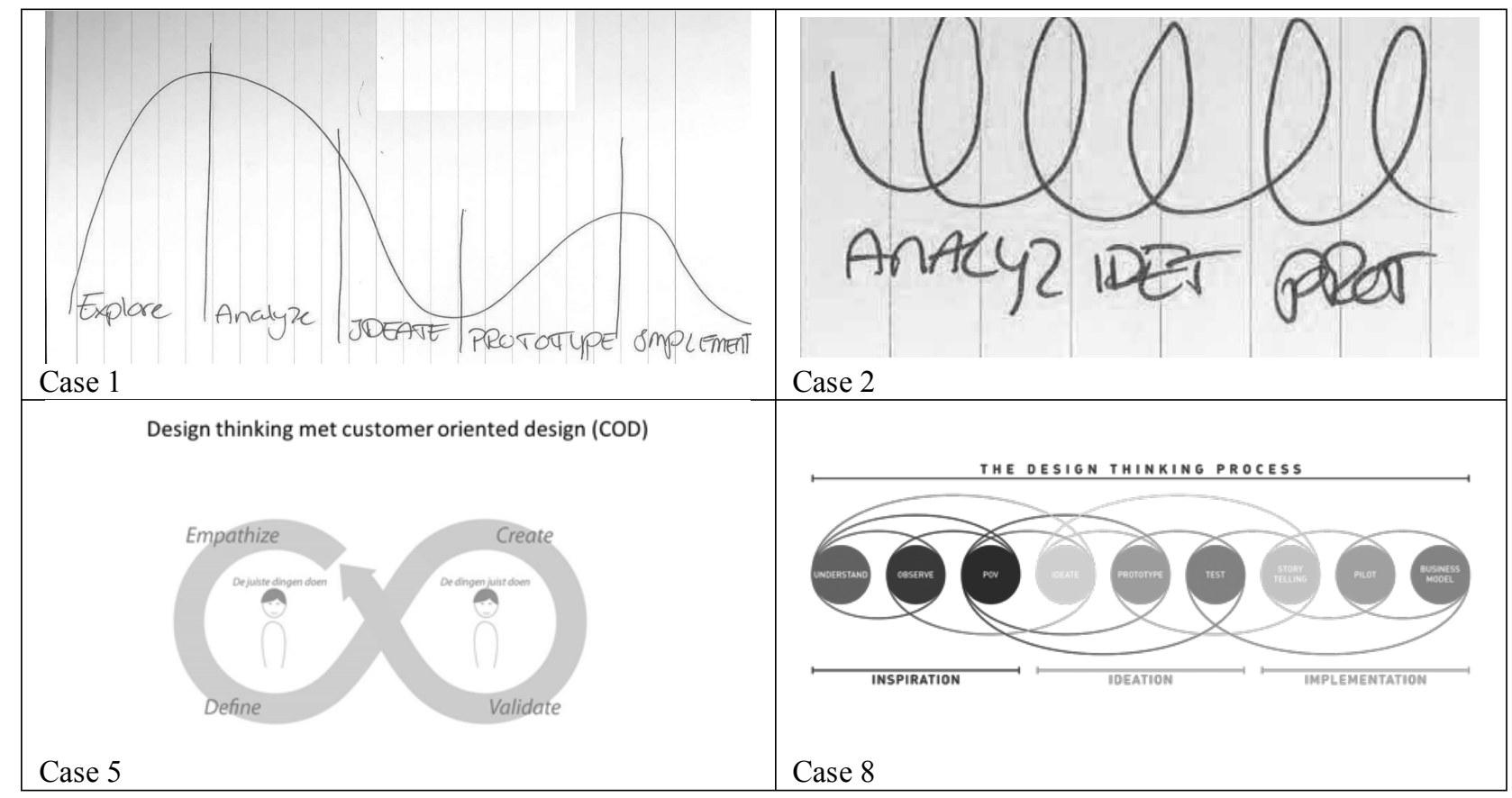

Figure 1. Samples of 'Design Thinking Process' visualizations supplied by interviewees

ability of interviewees to merely theorize. Secondly, cases needed to include individuals that had used DT first-hand during the process which could be reflected upon. Lastly, as the question also focuses on adoption, the environment of corporate, service oriented organizations was chosen to represent the current industry trends and academic relevancy [7]. For an overview of cases and corresponding interviewees, see table 1 .

Data collection was established through in-depth interviews with interviewees that worked on service innovation projects and actively utilized DT during one or more of the projects. During the interview, interviewees were asked to identify the relevant project themselves and afterwards to nominate peers that worked on the same project. This resulted in an interviewee base with a variety of professions, representing reality to a certain degree (i.e. not only designers made use of DT, also innovation or business managers). Interviews lasted between 30 - 50 minutes and consisted of five semi-structured, open-ended questions which were developed based on the literature derived propositions. Initial questions were focused on 'why' and 'how' DT was used, referring to the application and expectation elements of the research question. In addition, interviewees were asked to reflect upon the project more in-depth to explain the process (application form) and to explain what went well during the process (expected adoption benefits) and not so well (adoption challenges). To increase the causal nature of the research, probe questions were used to reveal the rationale behind arguments. As an additional form of data collection, documentation was supplied or requested when appropriate, to increase the amount and diversity of evidence as well as to deepen the understanding of the interviewee's given arguments. This took shape in figures, in-person drawings, internal presentations or videos. Specifically, in cases with limitations of single informants, documentation was requested to increase validity.

From the recorded interviews and provided documents, case reports were drafted consisting of partial transcription and document evaluations. Case reports were coded with codes being developed iteratively and inductively. Still, codes were sampled reflecting the concepts that proved to have theoretical relevance [32]. Documents were evaluated considering the purpose of the document, the author, the target audience and additional original sources of documents [33], such as established DT sources i.e. IDEO or Stanford D School. Even though documents were fragmented and often lacking text, they provided a behind-the-scene look and aided in establishing code category boundaries. The data from documents was analyzed together with interview data, in order to 
derive themes that emerged in both types of evidence. By focusing on within- and cross-case analysis, patterns emerged that provided for a better analysis of constructs related to the developed propositions P0 P4. This included relational patterns between constructs and themes.

\section{Findings}

\subsection{Adoption of Design Thinking}

To investigate how DT is utilized in regards to service innovations, the first proposition focusses on the application form of DT. Data showed limited support for $\mathrm{P0}$ - Design Thinking applied in practice is done by following stages or formal methods. Not because evidence did not show processes or methods were used during application, but because the relationship to DT appeared to be that of a moderator to the 'mindset' of DT. Throughout the interview several forms of application were described or mentioned, such as 'tools', 'processes' and 'methods':

"We always try to go through the process with as many colleagues as possible, that are relevant for our project."

"...certain tools are getting handed-over to other departments, so they can use it on their own."

"... we used tools to make people think broader and in a more holistic way about everything the customer went through in their life journey.",

Supplied documentation from four out of eight cases supported this description, by showcasing visualizations of a 'design thinking process' (see figure 1). Nonetheless, all interviewees mentioned either explicitly or implicitly that tools and processes were used to facilitate a 'way of thinking'. Interviewee (B) explained: "In the end it's about a mindset, not about the tools you use.". In contrast to the literature, a few interviewees ( $\mathrm{G}, \mathrm{H} \& \mathrm{I})$ who used DT in an individual effort, explained not to use tools or processes at all, as in some cases using tools or methods was not applicable. Such cases included for example business strategy development, or projects that were future oriented in such a way that customers or users did not recognize a need or want yet. Interviewee (I) explained: "It is quite difficult to use it for strategy development. ... because people view it and associate it as an application form due to the word 'design', rather than a way of thinking.'. However, all three interviewees referred to tools or processes at later stages. In these instances, tools were argued to be used as encouragement for (other) team-members to 'think in a different way', while processes provided 'guidance':

“... I tried to use an outside-in approach and include tools. ... it works because it forces people to think about it or to question it."

"It's good because it gives you a structure to follow, which provides control of the project flow."

This dynamic was also seen in DT utilization within a wider team. As interviewee (C) explained: “... very difficult to get them in a mindset where they have to think differently. Design Thinking Tools can help with this."

In conclusion, our findings do not support $\mathrm{P} 0$ (Design Thinking applied in practice is done by following stages or formal methods), instead showing that organizations and individuals apply DT as a mindset, without necessarily using tools and methods, though applying them when needed to stimulate this mindset.

\subsection{Adoption Benefits}

\subsubsection{Complexity Management}

Data showed that DT was used in cases that involved high complexity, in line with the argument of Kolko [7]. This was shown by the 'wicked' nature of projects that employees were asked to work on $[16,17]$ Many were introduced as a certain 'state' or 'problem' of a customer which needed solving, though not specifically knowing how to, or with what.

"We focused on freelancers and wanted to create a community. ... but we didn't have a clear idea about what problem we were trying to solve."

"Often the gap is not able to be solved in the system you're currently operating. ... therefore, people do not know how to.".

Another way in which project complexity revealed itself was in terms of project characteristics, such as terms of size, number of stakeholders, or variables such as information technology. As interviewee (C) described: "We had a basic idea of the proposition, but it was quite large and we wanted an end-to-end good experience. ... it also had a lot of IT.".

In concurrence with theory [3], interviewees showed to use DT for projects where contextual understanding and holistic solutions are desired. This can be seen in the type of cases such as services, service tools and value propositions. In these cases, understanding of the context is essential in order to develop a solution that when used by the customer, creates value [8]. Interviewee $(\mathrm{G})$ expressed this contextual relevance for case 6 . The project set out to develop an online platform, though when DT was applied, the project was put on hold. This was a result 
of a discrepancy between the solution that was being developed and the actual requirements of the end-user. Contextual circumstances made the online platform redundant. While elaborating the interviewee explained the rationale: "It's about how can we service the customer in its total journey, not just when he or she calls the bank.".

Many of the interviewees did not describe complexity management to be the specific motivation for applying DT, though implicitly pleaded for it. An example is the reasoning of interviewee (C) “... it works very well as it makes something quite complex understandable and tangible for people”. A single interviewee (A) however, did argue that application of DT is specifically for complex problems: "Design thinking is more for complex issues, it's not just a customer journey tool".

In conclusion, our case studies strongly support $P 1$ - Application of Design Thinking improves the ability to solve complex service innovation problems.

\subsubsection{Customer Value}

Data showed that ultimately DT was used with the expectation to increase value creation for the customer. All interviewees explained the motivation for utilizing DT was directly related to creation of solutions providing greater customer value. Interviewee (A) reported to believe the project delivered on this potential, as can be seen in the quote: "It was a very successful project, everything is implemented and we have had a lot of enthusiastic responses throughout the company, including those of customers.".

In agreement with literature, putting the customer central $[1,2,5,7,13,14]$ and understanding their needs [22] were argued to be at the base of being able to develop value creating innovations.

“... to build the proposition so it really matches the customer."

"... ensure that the customer is central to the strategy we develop."

"... to understand the customer as thoroughly as possible and based on this develop propositions."

"... you cannot skip the first parts. You need to have a solid understanding of the customer before you move on ..."

Interviewee (B) described how customer centricity and understanding were embedded in the project process: "We made a morphological framework ... and from that we were able to make five situational need profiles. ... we used it to base the offering upon.".

What interviewee (B) did in this situation is linking this understanding and customer centricity to the actual offering. Additional data showed that this connection between understanding and actually embedding in the actual project outcome is deemed essential. Interviewee (I) described about case (8) that an understanding of the customer's needs and wants were created, though were not embedded in the final solution. The interviewee's attitude towards this was negative, and she expected the solution not to deliver great customer value.

This finding is in line with the rationale that value creation in service innovation is ultimately determined by the beneficiary $[8,21]$, and thus needs to be embedded in the delivered solution. We find evidence for this across all case studies which supports $P 2$ Application of design thinking improves the ability to create solutions that deliver customer value.

\subsubsection{Complexity Management and Customer Value}

A pattern that was not specifically sought for, but which emerged from cross-case analysis is that of projects showing a high effort to manage complexity and improved (perceived) project results. Cases 1, 2 and 3 showed the use of processes, tools or specific facilities (e.g., a 'customer experience room') in their project process, with the purpose to 'bring various stakeholders together', 'analyze the situation' or to ensure 'did we think of everything'. The 3 cases also involved open and highly complex systems [8, 18]. This complexity was evidenced in the number of project stakeholders (case 1, 2, 3), technologies (1, 3) or organizations $(1,2)$. However, all case informants were of the opinion that the project delivered superior value to customers:

"... build the proposition so it really matches the customer."

"It was a very successful project, everything is implemented and we've had a lot of enthusiastic responses throughout the company and including customers."

The opposite relation was found as well, projects that involved a high degree of complexity though low effort of understanding this, were believed to deliver limited customer value (case 4, 6, 8). For example, case 6 was kicked off without any use of tools, processes or methods to understand the project's focus and its context. As interviewee (G) explained: “... we did not have a problem statement, so we didn't know what problem we were solving.". The project was put on hold, as proposed 'solutions' did not show to be solving any customer problems during validation. Thus, the project propositions were no solutions at all, they were not fulfilling any customer needs, and therefore not generating any customer value $(5,20)$. 
This relation between complexity and value creation has been argued in previous literature on services. For example, the link between social systems and value (co-)creation [35].

\subsection{Adoption Challenges}

\subsubsection{Individual Understanding}

The adoption of DT within the studied cases was either requested for by senior management (cases 1, 2, $5,8)$ or done out of individual motivation $(3,4,6,7)$. However, DT is generally not adopted throughout the organization as was experienced firsthand when many research requests were answered with "Design Thinking, what is that again?". This limited awareness of DT was also experienced by interviewees and perceived to be a challenge to adopting the approach. In particular, a lack of understanding the approach was believed to negatively impact the buy-in for DT adoption. As interviewee (C) explained: "During the project I also used a lot of stakeholder management and ways of creating buy-in. To convince people it is a good idea (using DT).". Interviewee (F) acknowledged this as well: "People want to put the customer central and use DT ... but they don't know how."

Data showed that DT adopters used several ways to develop an understanding of DT amongst colleagues or stakeholders, such as visualizations (cases 1, 2, 5, $7 \& 8$ ), videos (case 7) or workshops (cases 3, 5-8).

"Everybody uses the word (DT tool), but no-one really knows what the word means. So that's one of the things that we elaborate on in Design Thinking workshops. ... to explain what it is."

"We developed our own framework on request of the manager, ... so we can explain how to use it." (see figure 1, case 5).

An additional way of understanding DT was established through the role of facilitators [34]. This role was owned by several interviewees:

"... they don't know how. So, they use us, as facilitators for the process."

"You don't notice it yourself. However, we do get a lot of compliments like, the exercises were very refreshing and I think we got a lot of new ideas on the table."

The need for DT facilitators was also expressed from the opposite point of view by interviewee (G): "I would talk to someone like (designer) and ask how to conduct such an interview. Because I noticed that I would start thinking in solutions quite quickly."

Nonetheless, many interviewees elaborated that even when an understanding is established, adoption by project-members can still be challenging. As interviewee (A) illustrated on collaborating with market researchers during the project: "we have a difference in vision ... they do not like our approach. ... they do not believe that design thinking includes proper research.". This aligns with the literature on thought-worlds, ideas that do not fit one's own thought-world can be deemed meaningless and potentially be rejected $[25,27]$. Additional evidence regarding idea rejection is found when going back to case (8); initially DT was adopted by team members however disregarded at a later point within the project process. Interviewee (I) explained: "Because they (developers) fell back into their own ways of thinking and used their assumptions.".

Taken together, we conclude that our findings offer clear support for P3 - The adoption of design thinking is limited by an individual's understanding of the approach.

\subsubsection{Uncertainty Avoidance}

When interviewee $(\mathrm{H})$ explained that to build understanding he ensured other project team members experienced the DT application, he clarified: "Once it is used, you get a lot of buy-in. Take for example company $X$, they engaged with several agencies using design thinking and now they are working in-house with 150 students on design thinking driven projects.". As such he explained the desire of corporations to experience DT project successes before adopting the approach in-house. This desire for tangible results, known beforehand, is mentioned by many interviewees as being an obstacle to adopting the approach.

"As long as you cannot prove that it (the project) has direct effect on the sales, for example, is it very difficult to get these projects pushed forward...."

"Commercial goals are often at the top of the list and sometimes conflict with design thinking projects. Design Thinking projects often need to prove themselves first, ... it is difficult to predict that in advance."

"You can have a great project, that makes customers very happy though it is priced at 3 million. There are also 200 other projects of which 20 are cheaper and a no-brainer, so they win it over the 3 million project."

Thus, the limitation lies within the inability to forecast the project outcome and its tangible results. This corresponds with the literature on abductive reasoning [28] and the typical 'wicked' nature of problems DT is being applied to, which lack up front definite formulations and solutions $[16,17]$. However, the core issue is related to the uncertainty around what 
the outcome will be, resulting in disengagement from medium to long-term commitments [24]. This was explicitly mentioned and experienced by interviewee (D) when the project was rejected: “... because it was going to cost money and a bit of effort.... It's a company that is focused on short-term, and does not look at long-term benefits.".

Using an approach that is not (academically) validated also contributes towards this adoption barrier, as mentioned by interviewees $(\mathrm{H}) \&(\mathrm{~B})$. (H) indicated: “... a lack of company support. ... because the approach is not proven yet.", while (B) explained: "... there are not many frameworks that have been tested that show to be valid or credible.". This does not necessarily relate to literature directly, though it contributes towards the overall uncertainty of the project. A lack of a specific process and project duration showed to be undesired by organizations, though sometimes challenging for adopters to establish. As interviewee (A) explained: "You cannot say, we're going to execute this process. That's what the company prefers, including that they know that at the end of the process we have X. This is sometimes difficult."

In summary, these results offer firm support for $P 4$ - The adoption of design thinking is limited by an individual's uncertainty avoidance.

\subsubsection{Individual Understanding and Uncertainty Avoidance}

As described above, the avoidance of uncertainty is seen to be an obstacle to adopting design thinking during innovation projects. This challenge was identified out of the provided information of individual respondents, who experienced this during their DT adopted projects. In these cases, the individuals or project teams did not avoid the potential uncertainty and adopted DT. What all these cases also have in common, is that the project informants had an understanding of DT. However, during cross-case analysis an outlier indicated a discrepancy. Throughout case 4, the informant showed limited understanding of the approach, specifically in terms of experimentation and customer centrality (Liedtka, 2015): "How do you test a process or service that's not exciting yet? Then you almost have to do it manually." and "If you look at what the customer wants, then the current products in the market don't really solve that need. ... but we'll do it ... we have to start somewhere and pick up those first learnings.". As can be read in the second statement, DT was adopted though only during customer need analysis. When the uncertainty about what did solve the customer needs presented itself, DT was not adopted and instead market trends were followed. In short, controversial to the other cases, this case showed a lower individual understanding and also avoided uncertainty. This is the opposite pattern of what was found amongst the other cases.

\section{Discussion and Future Research}

Why and how is design thinking applied for service innovation projects, and what are the benefits of, and challenges to, adoption of design thinking? The findings from the case studies show that design thinking is applied in the form of a mindset rather than a process. When needed, tools, methods and process visualizations are found to be used to facilitate this mindset. This addresses the 'how' in the research question. However, even though critical to understanding what DT is, the application form is not translated into a hypothesis as there is limited constructive evidence to do so. The topic simply remains too abstract. Next to that, a 'mindset' or 'usage of tools and methods' in the way it is being discussed in this study, is not measurable and thus does not lend itself for a testable hypothesis. Nonetheless, the evidence of the real-life cases shows to be a new approach to DT application, and could be an interesting avenue towards developing a definition of DT.

To continue with answering the research question, the drivers to adopt design thinking were found to be twofold. First of all, DT is applied in an effort to manage and understand complexity. It helps individuals to solve problems and meet needs that have no definite formulation or a solution ('wicked problems'). Next to that, DT and related tools are expected to help to develop a specific contextual understanding of the wider system. As a result, DT was perceived to generate 'holistic' solutions that meet the totality of the project at hand. Secondly, DT is expected to increase the customer value delivery of projects. Core to this is the customer understanding and centricity, which forms the base for the project. However, it is essential that this is linked to the eventual project outcome. As such the innovation will ensure it meets the value expectations set by the beneficiary.

Based on the above adoption opportunities, DT is expected to be specifically valuable for service innovation as it supports the focus on value creation within complex configurations. Thereby, this study answers the quest for scientific understanding of ways to enhance design and innovation of service systems, making the case for DT as an approach to accomplish just that $[9,11,12]$. In addition, the findings presented in this paper contribute towards the academic 
discussion and understanding of the role and application of DT $[2,5,7]$. In order to work towards a generally accepted theory, the academic literature could benefit from research focusing on even more respondents studied longitudinally. With a focus on DT practices used during 'live' projects, and related to eventual value captured, it will distinguish optimal application forms for specified purposes.

In summary, we developed five propositions (P0$\mathrm{P} 4)$ and found clear support for all but one (P0, proposing that DT is applied by following stages or formal methods). In addition, our findings suggest that an increased understanding of DT will lead to less uncertainty avoidance and that an increased effort to manage complexity, positively influences (perceived) value creation. Taken together, this leads us to propose the model for DT adoption shown in Figure 2.

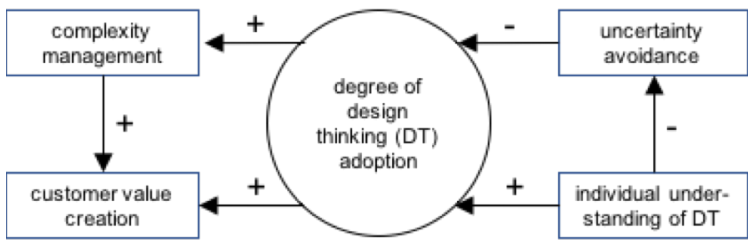

Figure 2. Design Thinking Adoption Model

This model depicts the empirical generalizations of the observed relationships and consistencies amongst the variables [38]. It is intended as a starting point for subsequent testing and empirical validation in the context of service innovation projects, doing so will not only result in knowledge contribution around an important topic, but may also contribute to a clear and shared understanding of the very nature of DT when applied in practical settings. If the above proposed model is correct, this has the added advantage of potentially increasing the 'individual understanding of DT', which is both directly as well indirectly (through uncertainty avoidance) hypothesized to be linked to the degree of DT adoption.

Exploring the role of 'individual understanding of DT' is therefore a first suggestion for future research. This could build on Dym et. al [39] who explored the contribution of project based learning (PBL) as a tool to teach engineering students about design thinking. Their finding that reinforced-learning-by-doing with the aid of coaching and tools (what PBL is largely about) is indeed beneficial to DT adoption (in their case by students), and could well translate to the world of service innovation. We find some evidence for this in our study; interviewees tend to use explicit methods and tools during projects to stimulate a DT mindset and create an understanding of the DT approach (see figure 1), and repeated experience shifts the focus away from those tools and processes to a DT mindset (see the discussion around P0). Exploring 'individual understanding of DT' may also help us to overcome possibly restrictive thought-worlds [10] that can act as adoption barriers.

\section{References}

[1] Seidel, V. P., \& Fixson, S. K. (2013). Adopting design thinking in novice multidisciplinary teams: The application and limits of design methods and reflexive practices. Journal of Product Innovation Management, 30 (1), 19-33.

[2] Liedtka, J. (2015). Perspective: linking design thinking with innovation outcomes through cognitive bias reduction. Journal of Product Innovation Management, 32(6), 925-938.

[3] Beverland, M. B., Wilner, S. J., \& Micheli, P. (2015). Reconciling the tension between consistency and relevance: design thinking as a mechanism for brand ambidexterity. Journal of the Academy of Marketing Science, 43 (5), 589609.

[4] Dorst, K. (2011). The core of 'design thinking' and its application. Design Studies, 32(6), 521-530.

[5] Gruber, M., De Leon, N., George, G., \& Thompson, P. (2015). Managing by design. Academy of Management Journal, 58(1), 1-7.

[6] Verganti, R. (2008). Design, meanings, and radical innovation: A metamodel and a research agenda. Journal of Product Innovation Management, 25(5), 436-456.

[7] Kolko, J. (2015). Design thinking comes of age. Harvard Business Review, 93(9), 66-71.

[8] Vargo, S. L., Maglio, P. P., \& Akaka, M. A. (2008). On value and value co-creation: A service systems and service logic perspective. European management journal, 26(3), 145-152.

[9] Ostrom, A. L., Bitner, M. J., Brown, S. W., Burkhard, K. A., Goul, M., Smith-Daniels, V., ... \& Rabinovich, E. (2010). Moving forward and making a difference: research priorities for the science of service. Journal of Service Research, 13(1), 4-36.

[10] Spohrer, J., \& Maglio, P. P. (2008). The emergence of service science: Toward systematic service innovations to accelerate co-creation of value. Production and operations management, 17(3), 238-246.

[11] Maglio, P. P., \& Spohrer, J. (2013). A service science perspective on business model innovation. Industrial Marketing Management, 42(5), 665-670.

[12] Maglio, P. P., \& Spohrer, J. (2008). Fundamentals of service science. Journal of the Academy of Marketing Science, 36(1), 18-20. 
[13] Brown, T (2009). Change by Design. HarperCollins Publishers

[14] Drews, C. (2009). Unleashing the full potential of design thinking as a business method. Design Management Review, 20(3), 38-44.

[15] Owen, C. (2007). Design thinking: Notes on its nature and use. Design Research Quarterly, 2(1), 16-27.

[16] Buchanan, R. (1992). Wicked problems in design thinking. Design issues, 8(2), 5-21.

[17] Tidd, J. (2001). Innovation management in context: environment, organization and performance. International Journal of Management Reviews, 3(3), 169-183.

[18] Maglio, P. P., Srinivasan, S., Kreulen, J. T., \& Spohrer, J. (2006). Service systems, service scientists, SSME, and innovation. Communications of the ACM, 49(7), 81-85.

[19] Woodruff, R. B. (1997). Customer value: the next source for competitive advantage. Journal of the academy of marketing science, 25(2), 139-153.

[20] Osterwalder, A., \& Pigneur, Y. (2010). Business model generation: a handbook for visionaries, game changers, and challengers. John Wiley \& Sons.

[21] Vargo, S. L., \& Lusch, R. F. (2008). Service-dominant logic: continuing the evolution. Journal of the Academy of marketing Science, 36(1), 1-10.

[22] Chesbrough, H., \& Spohrer, J. (2006). A research manifesto for services science. Communications of the ACM, 49(7), 35-40.

[23] Becker, S. W., \& Brownson, F. O. (1964). What price ambiguity? On the role of ambiguity in decision-making. Journal of Political Economy, 72(1), 62-73.

[24] Caballero, R. J., \& Krishnamurthy, A. (2008). Collective risk management in a flight to quality episode. The Journal of Finance, 63(5), 2195-2230.

[25] Dougherty, D. (1992). Interpretive barriers to successful product innovation in large firms. Organization science, 3 (2), 179-202.

[26] Eikhof, D. R., \& Haunschild, A. (2007). For art's sake! Artistic and economic logics in creative production. Journal of Organizational Behavior, 28(5), 523-538.

[27] Beverland, M. B., Micheli, P., \& Farrelly, F. J. (2016). Resourceful sensemaking: overcoming barriers between marketing and design in NPD. Journal of Product Innovation Management, 33(5), 628-648.

[28] Johnson, T. R., \& Krems, J. F. (2001). Use of current explanations in multicausal abductive reasoning. Cognitive Science, 25(6), 903-939.
[29] Bonabeau, E., Bodick, N., \& Armstrong, R. W. (2008). A more rational approach to new-product development. Harvard Business Review, 86 (3), 96.

[30] Eisenhardt, K.M. \& Graebner, M.E. (2007). Theory Building from Cases: Opportunities and Challenges. Academy of Management Journal, 50(1), 25-32.

[31] Yin, R. K. (2013). Case study research: Design and methods. Sage publications.

[32] Strauss, A. \& Corbin, J. (1990). Basics of qualitative research: Grounded theory procedures and techniques. Newbury Park, CA: Sage.

[33] Bowen, G. A. (2009). Document analysis as a qualitative research method. Qualitative research journal, 9(2), 27-40.

[34] Schwarz, R. (2002). The skilled facilitator: A comprehensive resource for consultants, facilitators, managers, trainees, and coaches. John Wiley \& Sons.

[35] Edvardsson, B., Tronvoll, B., \& Gruber, T. (2011). Expanding understanding of service exchange and value cocreation: a social construction approach. Journal of the Academy of Marketing Science, 39(2), 327-339.

[36] Kwak, Y. H., \& Anbari, F. T. (2006). Benefits, obstacles, and future of six sigma approach. Technovation, 26(5), 708-715.

[37] Moe, N. B., Dingsøyr, T., \& Dybå, T. (2010). A teamwork model for understanding an agile team: A case study of a Scrum project. Information and Software Technology, 52(5), 480-491.

[38] Bourgeois III, L. J., \& Eisenhardt, K. M. (1988). Strategic decision processes in high velocity environments: Four cases in the microcomputer industry. Management Science, 34(7), 816-835.

[39] Dym, C. L., Agogino, A. M., Eris, O., Frey, D. D., \& Leifer, L. J. (2005). Engineering design thinking, teaching, and learning. Journal of Engineering Education, 94(1), 103120. 